\title{
Sidewise mask ventilation for pediatric anesthesia
}

\section{Dear Editor,}

Inhalation or intravenous anesthesia along with controlled or assisted mask ventilation is frequently used for interventions with short duration in pediatric patients, especially in surgical centers with high turnover and when laryngeal mask airways do not fit. To achieve one-handed mask ventilation the anesthesiologist has to stand behind the head, and the mask is held with one hand against the face, applying downward pressure on the mask body exerted by the thumb and the index finger (the thumb and the index finger have a " $C$ " shape) while the middle and the ring finger grasp the mandible to facilitate extension of the neck ${ }^{1}$. However, during interventions involving the upperhead (eye, forehead or scalp), one must share the place over the head of the patient with the surgical team and, occasionally, the mask ventilation must be ceased. In such situations, in order not to limit the surgical working place, it can be offered sidewise mask ventilation (SMV) where the anesthesiologist stands on one lateral side of the patient (Figure 1).

During SMV, the anesthesiologist stands at one lateral side of the patient (if he uses his left hand for mask holding he stands at the right side of the patient), the thumb thrusts the jaw by lifting the tip of the chin, while index and middle finger forming a "V" shape give downward pressure on the mask body (Figure 1-2). A transparent facemask, which is large enough to allow the mouth to remain open and does not cover the child's eyes, is recommended as in the classical application of facemask ventilation.

It is difficult to know how widely that technique is used, but it had been mentioned in a single study as 'lateral mask ventilation' by Maisch et al. ${ }^{2}$. They tested SMV in resuscitation simulations performed by a single rescuer. We could not find any description about this technique in anesthesia literature, but we think many pediatric anesthesiologists find out SMV by themselves during practice. Also, in adult patients, when the mask does not fit the face, an assistant can help mask ventilation as a second sidewise hand to prevent air leakage. Excessive pressure on the soft tissues of the neck, which can cause airway obstruction, is less related to SMV.

SMV may not be easy as classic application of mask ventilation, but it can be improved by practice and applied to short procedural cases involving the upper head.

Mefkur Bakan, MD, Assist. Prof., Ufuk Topuz, MD, Assist. Prof., Gokcen Basaranoglu, MD, Assist. Prof. Erdogan Ozturk, MD, Assoc. Prof.

Bezmialem Vakif University, Faculty of Medicine, Department of Anesthesiology and Reanimation Istanbul, Turkey

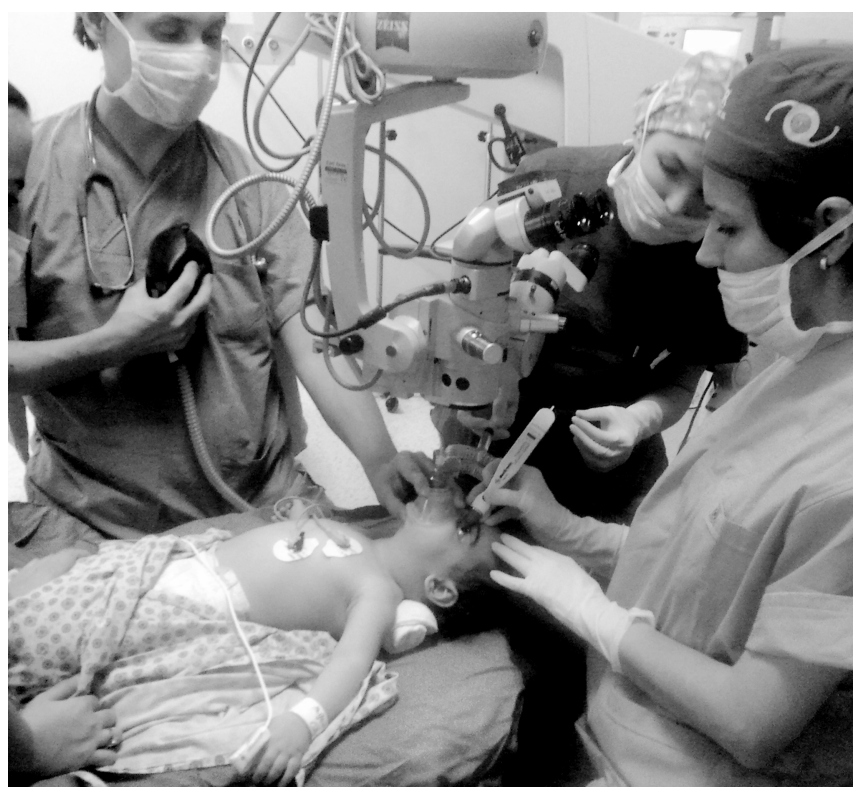

Figure 1 - Inhalational Anesthesia along with Sidewise Mask Ventilation during Eye Examination of a Child.

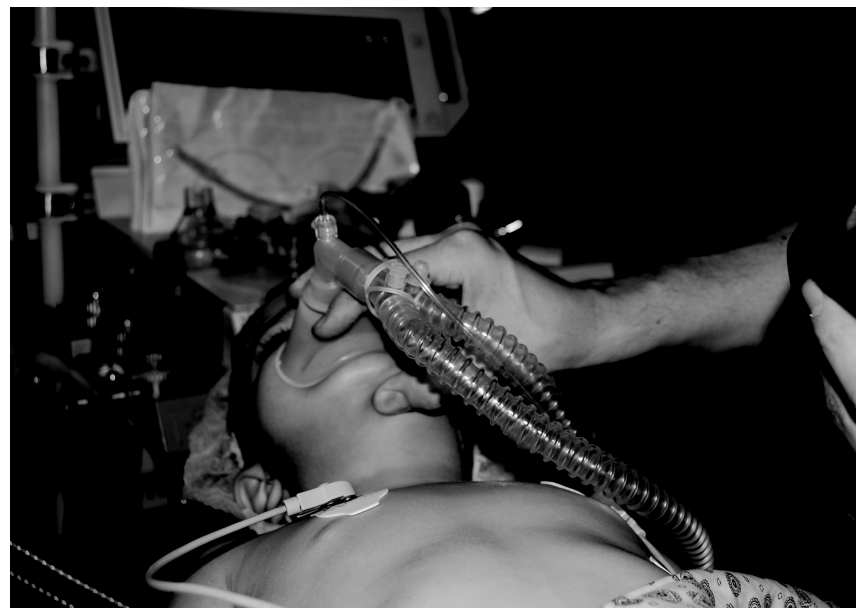

Figure 2 - Sidewise Mask Holding Technique. 


\section{REFERÊNCIAS/REFERENCES}

1- Stone DJ, Gal TJ - Airway management. In: Miller RD, ed. Anesthesia, $5^{\text {th }}$ edition, Philadelphia: Churchill Livingstone Inc; 2000. pp. 14141451.

2- Maisch S, Gamon E, Ilisch A, Goetz AE, Schmidt GN - Comparison of the over-the-head, lateral and alternating positions during cardiopulmonary resuscitation performed by a single rescuer with a bag-valvemask device. Emerg Med J, 2011;28:974-978. 